\title{
Multi-Objective Optimization of Cutting Parameters in Turning AISI 304 Austenitic Stainless Steel
}

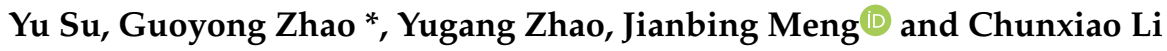 \\ School of Mechanical Engineering, Shandong University of Technology, Zibo 255000, China; \\ 18753391805@163.com (Y.S.); zhaoyg9289@126.com (Y.Z.); jianbingmeng@126.com (J.M.); \\ 19862576051@163.com (C.L.) \\ * Correspondence: zgy709@sdut.edu.cn; Tel.: +86-0533-278-7910
}

Received: 17 January 2020; Accepted: 1 February 2020; Published: 3 February 2020

\begin{abstract}
Energy conservation and emission reduction is an essential consideration in sustainable manufacturing. However, the traditional optimization of cutting parameters mostly focuses on machining cost, surface quality, and cutting force, ignoring the influence of cutting parameters on energy consumption in cutting process. This paper presents a multi-objective optimization method of cutting parameters based on grey relational analysis and response surface methodology (RSM), which is applied to turn AISI 304 austenitic stainless steel in order to improve cutting quality and production rate while reducing energy consumption. Firstly, Taguchi method was used to design the turning experiments. Secondly, the multi-objective optimization problem was converted into a simple objective optimization problem through grey relational analysis. Finally, the regression model based on RSM for grey relational grade was developed and the optimal combination of turning parameters $\left(a_{p}=2.2 \mathrm{~mm}, f=0.15 \mathrm{~mm} / \mathrm{rev}\right.$, and $v=90 \mathrm{~m} / \mathrm{s}$ ) was determined. Compared with the initial turning parameters, surface roughness (Ra) decreases $66.90 \%$, material removal rate (MRR) increases $8.82 \%$, and specific energy consumption (SEC) simultaneously decreases $81.46 \%$. As such, the proposed optimization method realizes the trade-offs between cutting quality, production rate and energy consumption, and may provide useful guides on turning parameters formulation.
\end{abstract}

Keywords: AISI 304 austenitic stainless steel; multi-objective optimization; cutting parameters; specific energy consumption; grey relational analysis; response surface methodology (RSM)

\section{Introduction}

Cutting process is the main means of mechanical manufacturing, which plays an important role in the manufacturing industry. It was found that the formulation of cutting parameters has significant influence on cutting quality, production rate, and energy consumption [1-3]. In general, most of the cutting parameters are determined according to engineering experience and specialized handbooks, which cannot obtain the optimal machining effect. Consequently, the optimization of cutting parameters for different objectives has always been a hot issue in manufacturing enterprises and academia.

The surface integrity, machining efficiency, and cutting force are usually taken as objectives in most of the traditional optimization of cutting parameters. For example, Kumar [4] adopted surface roughness and material removal rate (MRR) as objectives to optimize the cutting parameters in turning C360 copper alloy. Zhou et al. [5] obtained the Pareto optimal solution with the maximum MRR and the minimum surface roughness in turning AISI 304 based on the genetic algorithm gradient boosting regression tree (GA-GBRT) model they established. Their experimental results demonstrated that MRR can be improved by increasing cutting depth and cutting speed in a small range of surface roughness variations. In addition, the grey relational analysis is often used as a powerful tool when dealing with 
multi-objective optimization of cutting parameters. Using grey relational analysis, Li and Wang [6] optimized the grinding parameters, which effectively reduces the workpiece surface roughness and flatness. Kuram and Ozcelik [7] measured MRR, cutting force, and surface roughness in micro-milling Al 7075 and used grey relational analysis to determine the optimal combination of milling parameters with these three machining characteristics as objectives. Significant work has been carried out based on machining science and cost consideration. However, the influence of cutting parameters on energy consumption in cutting process is not considered in the aforementioned research.

The rapid development of the manufacturing industry has brought great convenience to human society, while exacerbating the problem of resource shortage and environmental pollution as well [2]. As the basic unit in machining systems, machine tool has large quantity with high energy consumption [8]. Vijayaraghavan et al. [9] suggested that reducing the energy consumption of machine tool can dramatically improve the environmental performance of the manufacturing industry. Thus, many scholars have studied energy consumption characteristics of machine tool in order to improve the energy efficiency of machine tool. Based on the investigation of the relationship between energy consumption of machine tool and MRR, Kara and Li [10] proposed an energy consumption prediction model suitable for turning and milling processes. On this basis, Li et al. [11] improved the energy consumption prediction model of milling processes with taking the spindle speed into consideration. Moreover, Zhang et al. [12] developed the specific energy consumption (SEC) model based on cutting parameters and analyzed the influence of cutting parameters on SEC. These research projects show that the energy consumption of machine tool can be reduced by selecting reasonable cutting parameters, laying the foundation for energy efficiency optimization of machine tool.

Recently, the optimization of cutting parameters aiming at energy saving and emission reduction has become a research hotspot in sustainable manufacturing. For reducing the energy consumption of machine tool, Camposeco-Negrete [13] optimized the cutting parameters in turning of AISI 6061 T6 aluminum by using Taguchi method and ANOVA. His research also pointed out that higher feed speed provides minimum energy consumption but will lead to higher surface roughness. It is worth noticing that the optimal cutting parameters for one machining characteristic may worsen other machining characteristics. Hence, the multi-objective optimization of cutting parameters based on both technique requirements and energy-saving consideration is more reasonable in actual machining. Zhao et al. [14] optimized the milling parameters through grey relational analysis, which can reduce energy consumption and improve surface quality simultaneously. In order to minimize the cutting time and energy consumption per unit of removed material, Zhou et al. [15] proposed a multi-objective optimization model and obtained the optimal cutting parameters by genetic algorithm (GA). Similarly, Li et al. [16] established the RSM models of energy efficiency and cutting time, and optimized milling parameters through particle swarm optimization algorithm (PSOA). Yan and Li [17] presented an approach for optimization of milling parameters with multiple responses such as cutting energy consumption, surface roughness, and MRR, which integrated the weighted grey relational analysis and RSM. Furthermore, Li et al. [18] explored the influence of cutting parameters on tool wear and surface topography in turning AISI 304, and optimized the cutting parameters with the goal of the maximum MRR and the minimum specific cutting energy.

Based on the above literature, it is noted that the optimization of cutting parameters has changed from single objective optimization to multi-objective optimization considering both technique requirements and environmental performance. Although recent work has made valuable contributions towards energy conservation and emission reduction, the optimization of cutting parameters for sustainable manufacturing requires more comprehensive study, especially for some difficult-to-machine materials. Therefore, the objectives of this paper are to: (1) Investigate the multi-objective optimization framework of turning parameters for sustainable manufacturing; (2) propose the multi-objective optimization method based on grey relational analysis and RSM; (3) verify the optimization method with wet turning experiments of AISI 304 austenitic stainless steel. 


\section{Multi-Objective Optimization Framework of Turning Parameters}

Lathes account for about $20-35 \%$ of the total number of cutting machine tool. They are mainly used for machining various rotating surfaces, such as internal cylindrical surfaces, external cylindrical surfaces, and conical surfaces. The traditional turning process improves production rate as much as possible on the premise of guaranteeing the cutting quality. However, the energy consumption of machine tool and the adverse effects on the environment are ignored.

In a specific machining system, the selection of cutting parameters becomes the basis of process optimization. For the turning process oriented to sustainable manufacturing, the optimization objectives should be expanded to cutting quality, production rate, and energy consumption. Surface roughness, MRR, and SEC are featured as evaluation criteria of machining characteristics. Therefore, the multi-objective optimization framework of turning parameters can be outlined in Figure 1 and the optimization problem can be described as Equation (1).

$$
\left\{\begin{array} { c } 
{ \operatorname { m i n } R a ( a _ { p } , f , v ) } \\
{ \operatorname { m a x } M R R ( a _ { p } , f , v ) } \\
{ \operatorname { m i n } S E C ( a _ { p } , f , v ) }
\end{array} \quad \left\{\begin{array}{c}
a_{p \min } \leq a_{p} \leq a_{p \max } \\
f_{\min } \leq f \leq f_{\max } \\
v_{\min } \leq v \leq v_{\max }
\end{array}\right.\right.
$$

where $R a$ is surface roughness, $M R R$ is material removal rate, SEC is specific energy consumption of machine tool, $a_{p}$ is cutting depth, $f$ is feed speed, and $v$ is cutting speed.

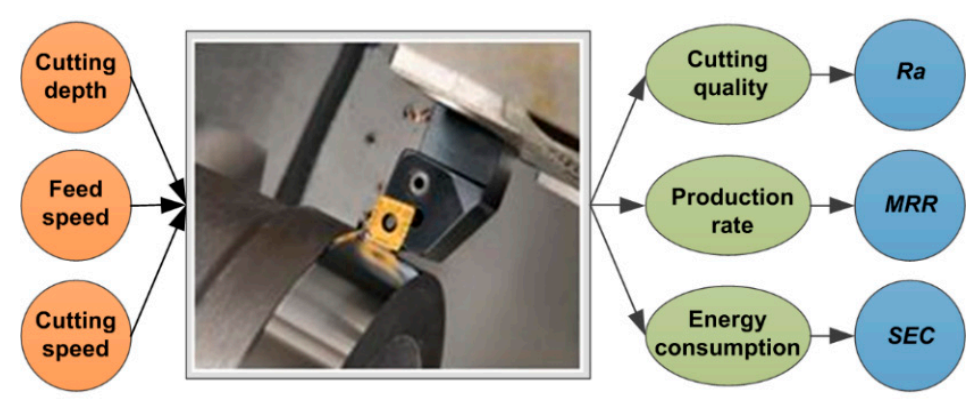

Figure 1. Multi-objective optimization framework of turning parameters.

\subsection{Cutting Quality}

The surface quality usually has a great influence on mechanical performance of parts [19]. It has been proved that the scrapping of many mechanical products is caused by the surface defects of parts. Surface roughness is therefore considered as a vital technical requirement in cutting process. Moreover, it was found that surface roughness is closely related to cutting conditions, especially cutting parameters [20].

\subsection{Production Rate}

MRR, as one of the criteria for evaluating production rate, is widely used for cutting process optimization. While the traditional selection of cutting parameters is conservative, which is not conducive to the realization of efficient machining. The value of MRR when turning external cylindrical surface can be calculated using Equation (2).

$$
M R R=\frac{\pi\left[\left(\frac{d}{2}\right)^{2}-\left(\frac{d}{2}-a_{p}\right)^{2}\right] n f}{60}
$$

where $d$ is workpiece diameter in $\mathrm{mm}, n$ is spindle speed in rev/min, $f$ is feed speed in $\mathrm{mm} / \mathrm{rev}$, and $a_{p}$ is cutting depth in $\mathrm{mm}$. 


\subsection{Energy Consumption}

In general, the cutting stage is the most energy-consuming work process of machine tool. In this stage, the energy consuming components include machine control unit (MCU), spindle motor, feed-axis motors, cooling pump motor, and lighting device. The energy consumption can be obtained by monitoring the power consumption of machine tool [21].

SEC expresses the required energy consumption when cutting unit volume material and can be computed by Equation (3). Moreover, the advantage of SEC is that as long as the specific energy consumption is achieved, the machine tool energy consumption in machining can be predicted accurately.

$$
S E C=\frac{E}{Q}=\frac{P \cdot t}{M R R \cdot t}=\frac{P}{M R R}
$$

where $E$ is machine tool energy consumption in $\mathrm{J}$, Q is material removal volume in $\mathrm{mm}^{3}, P$ is total power of machine tool in cutting stage in $\mathrm{W}, M R R$ is material removal rate in $\mathrm{mm}^{3} / \mathrm{s}$, and $t$ is cutting time in $\mathrm{s}$.

\section{Optimization Example}

\subsection{Experimental Details}

\subsubsection{Workpiece Material and Cutting Tool}

AISI 304 austenitic stainless steel is used widely in machinery, aerospace, and medical device industry because of its good overall performance. However, it also belongs to one of the difficult-to-machine materials due to its high toughness, serious work hardening, and bad thermal conductivity. AISI 304 was chosen as workpiece material, and its chemical composition and physical properties are shown in Tables 1 and 2. In addition, the workpiece diameter is $55 \mathrm{~mm}$ and cutting length is $120 \mathrm{~mm}$. The experiments were carried out with hard alloy external turning inserts CNMG 120408-PG SC2035.

Table 1. Chemical composition of AISI 304 austenitic stainless steel.

\begin{tabular}{ccccccccccc}
\hline Composition & $\mathbf{C}$ & $\mathbf{M n}$ & $\mathbf{S i}$ & $\mathbf{P}$ & $\mathbf{S}$ & $\mathbf{N i}$ & $\mathbf{C r}$ & $\mathbf{M o}$ & $\mathbf{C u}$ & $\mathbf{F e}$ \\
\hline $\mathrm{wt}^{2} \%$ & 0.065 & 1.78 & 0.3 & 0.027 & 0.02 & 8.1 & 18.2 & 0.13 & 0.14 & 71.2 \\
\hline
\end{tabular}

Table 2. Physical properties of AISI 304 austenitic stainless steel.

\begin{tabular}{|c|c|c|c|c|}
\hline Specific Heat Capacity & Elastic Modulus & Coefficient of Thermal Expansion & Thermal Conductivity & Density \\
\hline$\left(\mathrm{J} \cdot \mathrm{kg}^{-1} \cdot \mathrm{K}^{-1}\right)$ & (GPa) & $\left(10^{-6} \cdot K^{-1}\right)$ & $\left(\mathrm{W} \cdot \mathrm{m}^{-1} \cdot \mathrm{K}^{-1}\right)$ & $\left(\mathrm{g} / \mathrm{cm}^{3}\right)$ \\
\hline 500 & 194 & 17.3 & 16.3 & 7.93 \\
\hline
\end{tabular}

\subsubsection{Experimental Equipment}

Wet turning AISI 304 round bars and power measurement were performed and are shown in Figure 2. The computer numerical control (CNC) lathe is Yishui CKJ6163 (Yishui Inc., Shandong, China), with a maximum spindle speed of $1000 \mathrm{rev} / \mathrm{min}$, a maximum spindle power of $11 \mathrm{~kW}$, and a cooling pump power of $0.125 \mathrm{~kW}$. The power analyzer WT500 (Yokogawa, Tokyo, Japan) and sensors were adopted to measure power consumption from the lathe input lines. Three-phase power signals were connected to WT500 and recorded with WTViewerEfree software. In addition, the surface roughness tester RTP120 (Shjingmi Inc., Shanghai, China) was employed to measure the workpiece machined surface roughness. 


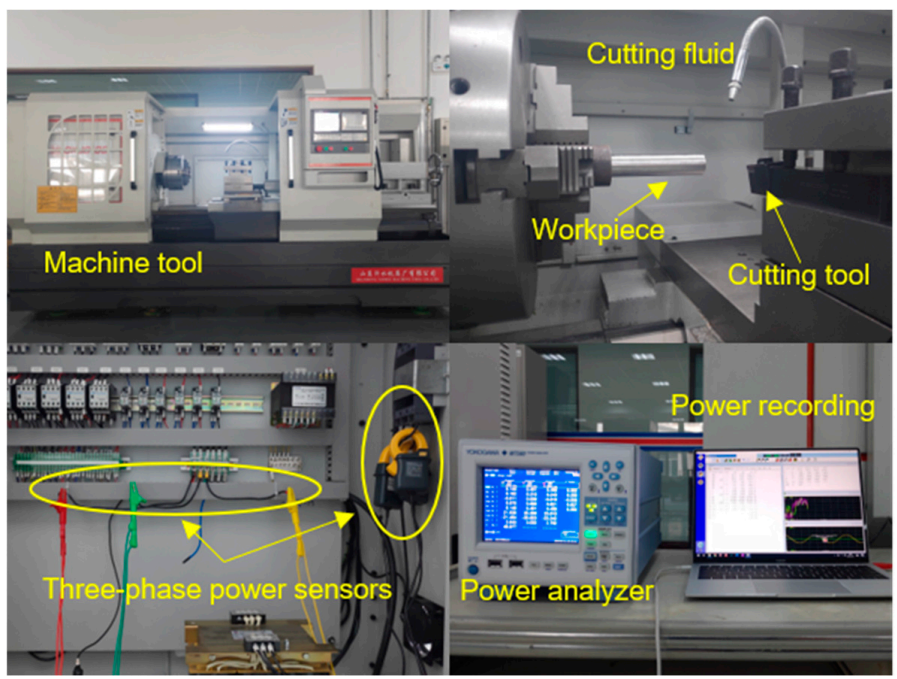

Figure 2. Experimental processing and measuring equipment.

\subsubsection{Design of Experiments}

The variances of cutting depth $\mathrm{a}_{\mathrm{p}}$, feed speed $\mathrm{f}$, and cutting speed v were customized according to the capacity of the lathe and the cutting inserts. Table 3 shows the cutting parameters and their levels. Taguchi method was used to design the $\mathrm{L}_{25}\left(5^{3}\right)$ orthogonal experiments with three factors and five levels, as shown in Table 4. The initial cutting parameter used the recommended value, cutting depth of $1.2 \mathrm{~mm}$, feed speed of $0.25 \mathrm{~mm} / \mathrm{rev}$, and cutting speed of $90 \mathrm{~m} / \mathrm{min}$.

Table 3. Cutting parameters and their levels.

\begin{tabular}{ccccccc}
\hline Parameters & Range & Level 1 & Level 2 & Level 3 & Level 4 & Level 5 \\
\hline$a_{p}(\mathrm{~mm})$ & $0.2-2.2$ & 0.2 & 0.7 & 1.2 & 1.7 & 2.2 \\
$f(\mathrm{~mm} / \mathrm{rev})$ & $0.15-0.35$ & 0.15 & 0.20 & 0.25 & 0.30 & 0.35 \\
$v(\mathrm{~m} / \mathrm{min})$ & $50-90$ & 50 & 60 & 70 & 80 & 90 \\
\hline
\end{tabular}

Table 4. Experiment design using $\mathrm{L}_{25}\left(5^{3}\right)$ orthogonal array and their measurement results.

\begin{tabular}{|c|c|c|c|c|c|c|c|c|}
\hline No. & $\begin{array}{c}a_{p} \\
(\mathrm{~mm})\end{array}$ & $\begin{array}{c}f \\
(\mathrm{~mm} / \mathrm{rev})\end{array}$ & $\frac{v}{(\mathrm{~m} / \mathrm{min})}$ & $\frac{d}{(\mathrm{~mm})}$ & $\frac{n}{(\mathrm{r} / \mathrm{min})}$ & $\frac{R a}{(\mu \mathrm{m})}$ & $\begin{array}{c}\text { MRR } \\
\left(\mathrm{mm}^{3} / \mathrm{s}\right)\end{array}$ & $\begin{array}{c}\text { SEC } \\
\left(\mathrm{J} / \mathrm{mm}^{3}\right)\end{array}$ \\
\hline 1 & 0.2 & 0.15 & 50 & 47.40 & 336 & 1.0325 & 24.9116 & 73.8180 \\
\hline 2 & 0.2 & 0.20 & 60 & 46.97 & 407 & 1.5835 & 39.8676 & 56.2968 \\
\hline 3 & 0.2 & 0.25 & 70 & 46.55 & 479 & 2.3270 & 58.1238 & 46.4650 \\
\hline 4 & 0.2 & 0.30 & 80 & 46.13 & 621 & 3.0725 & 89.6062 & 39.1952 \\
\hline 5 & 0.2 & 0.35 & 90 & 45.71 & 627 & 3.9995 & 104.5854 & 34.9219 \\
\hline 6 & 0.7 & 0.15 & 60 & 45.29 & 422 & 0.9995 & 103.4517 & 25.0040 \\
\hline 7 & 0.7 & 0.20 & 70 & 43.87 & 508 & 1.6190 & 160.7579 & 19.7991 \\
\hline 8 & 0.7 & 0.25 & 80 & 42.44 & 600 & 2.3195 & 229.4776 & 16.4892 \\
\hline 9 & 0.7 & 0.30 & 90 & 41.03 & 699 & 3.0820 & 309.9726 & 14.3977 \\
\hline 10 & 0.7 & 0.35 & 50 & 39.60 & 402 & 3.8170 & 200.6044 & 13.6178 \\
\hline 11 & 1.2 & 0.15 & 70 & 38.17 & 584 & 0.8830 & 203.4855 & 18.3305 \\
\hline 12 & 1.2 & 0.20 & 80 & 35.74 & 713 & 1.6265 & 309.4723 & 14.9285 \\
\hline 13 & 1.2 & 0.25 & 90 & 33.32 & 860 & 2.4110 & 433.9042 & 13.2391 \\
\hline 14 & 1.2 & 0.30 & 50 & 30.93 & 515 & 3.1150 & 288.6046 & 12.3712 \\
\hline 15 & 1.2 & 0.35 & 60 & 46.98 & 407 & 3.8100 & 409.7492 & 1.4578 \\
\hline 16 & 1.7 & 0.15 & 80 & 44.56 & 572 & 0.7810 & 327.3309 & 1.9894 \\
\hline 17 & 1.7 & 0.20 & 90 & 41.14 & 697 & 1.4180 & 489.3811 & 1.5024 \\
\hline 18 & 1.7 & 0.25 & 50 & 37.67 & 423 & 2.1520 & 338.5855 & 2.3185 \\
\hline 19 & 1.7 & 0.30 & 60 & 34.28 & 557 & 3.0020 & 484.5907 & 1.4280 \\
\hline 20 & 1.7 & 0.35 & 70 & 30.90 & 721 & 3.8335 & 655.8941 & 1.1752 \\
\hline 21 & 2.2 & 0.15 & 90 & 46.85 & 612 & 0.7980 & 472.1559 & 2.4545 \\
\hline 22 & 2.2 & 0.20 & 50 & 42.40 & 376 & 1.4105 & 348.2292 & 3.1293 \\
\hline 23 & 2.2 & 0.25 & 60 & 37.03 & 516 & 1.7555 & 517.5645 & 2.1792 \\
\hline 24 & 2.2 & 0.30 & 70 & 32.58 & 684 & 2.8110 & 718.1025 & 1.4547 \\
\hline 25 & 2.2 & 0.35 & 80 & 43.53 & 585 & 3.6870 & 974.7890 & 1.1535 \\
\hline
\end{tabular}


Before each set of experiments, the spindle speed was calculated according to Equation (4) for CNC programming.

$$
n=\frac{1000 v}{\pi d}
$$

where $v$ is cutting speed in $\mathrm{m} / \mathrm{min}, d$ is workpiece diameter in $\mathrm{mm}$, and $n$ is spindle speed in rev/min.

After each set of experiments, the workpiece surface roughness was measured from three different locations, and the average value was taken as the surface roughness Ra in each experiment. The MRR and SEC under each set of cutting parameters were obtained according to Equation (2) and (3), respectively. Twenty-five sets of experimental results are summarized in Table 4.

Because the size of workpiece was small and turning experiments were performed using cutting fluid, the tool wear was not serious. In addition, all experiments used new cutting inserts and the tool flank wear was less than $0.10 \mathrm{~mm}$. Therefore, the influence of tool wear was not considered in the paper.

\subsection{Grey Relational Analysis}

The advantage of grey relational analysis is that it can transform the complex multi-objective optimization problem into a single objective optimization problem through the calculation of grey relational grade (GRG). The calculation of GRG includes the following three steps [22].

Firstly, preprocess the experimental results of Ra, MRR, and SEC to avoid the effect of adopting different units. If the original data sequence is 'the-smaller-the-better', then this original data sequence is preprocessed using Equation (5); if the original data sequence is 'the-larger-the-better', then this original data sequence is preprocessed using Equation (6).

$$
\begin{gathered}
x_{i}^{*}(k)=\frac{\max x_{i}^{\circ}(k)-x_{i}^{\circ}(k)}{\max x_{i}^{\circ}(k)-\min x_{i}^{\circ}(k)} \\
x_{i}^{*}(k)=\frac{x_{i}^{\circ}(k)-\min x_{i}^{\circ}(k)}{\max x_{i}^{\circ}(k)-\min x_{i}^{\circ}(k)} \\
i=1,2, \ldots, m ; k=1,2, \ldots, z
\end{gathered}
$$

where $m$ is the number of experiments, $z$ is the number of data sequences, $x_{i}^{\circ}(k)$ is the original data sequence, $\max x_{i}^{\circ}(k)$ is the maximum value in the original data sequence, $\min x_{i}^{\circ}(k)$ is the minimum value in the original data sequence, and $x_{i}^{*}(k)$ is the contrast sequence. In this optimization example, the smaller Ra, the larger MRR, and the smaller SEC are desired. Therefore, the data sequences Ra, MRR, and SEC were preprocessed by Equation (5), Equation (6), and Equation (5), respectively. The results of data preprocessing are shown in Table 5 .

Secondly, calculate the grey relational coefficient (GRC) based on the results of data preprocessing.

$$
\begin{gathered}
\xi_{i}(k)=\frac{\Delta \min +\varphi \Delta \max }{\Delta_{o i}(k)+\varphi \Delta \max } \\
\Delta_{o i}(k)=\left|X^{o}(k)-x_{i}^{*}(k)\right| \\
\Delta \min =\min _{\forall j \in i} \min _{\forall k}\left|X^{o}(k)-x_{j}^{*}(k)\right| \\
\Delta \max =\max _{\forall j \in i} \max _{\forall k}\left|X^{o}(k)-x_{j}^{*}(k)\right|
\end{gathered}
$$

where $\xi_{i}(k)$ is GRC, $X^{o}(k)$ is the reference sequence and $X^{o}(k)=1, \Delta_{o i}(k)$ is the deviation value between $X^{o}(k)$ and $x_{i}^{*}(k)$, and $\varphi$ is the distinguishing coefficient and $\varphi=0.5$ normally. 
Table 5. The results of data preprocessing.

\begin{tabular}{cccc}
\hline Contrast Sequence & $\boldsymbol{R} \boldsymbol{a}$ & MRR & SEC \\
\hline 1 & 0.9219 & 0.0000 & 0.0000 \\
2 & 0.7507 & 0.0157 & 0.2411 \\
3 & 0.5197 & 0.0350 & 0.3764 \\
4 & 0.2880 & 0.0681 & 0.4765 \\
5 & 0.0000 & 0.0839 & 0.5353 \\
6 & 0.9321 & 0.0827 & 0.6718 \\
7 & 0.7396 & 0.1430 & 0.7434 \\
8 & 0.5220 & 0.2154 & 0.7890 \\
9 & 0.2851 & 0.3001 & 0.8177 \\
10 & 0.0567 & 0.1850 & 0.8285 \\
11 & 0.9683 & 0.1880 & 0.7636 \\
12 & 0.7373 & 0.2996 & 0.8104 \\
13 & 0.4936 & 0.4306 & 0.8337 \\
14 & 0.2748 & 0.2776 & 0.8456 \\
15 & 0.0589 & 0.4051 & 0.9958 \\
16 & 1.0000 & 0.3184 & 0.9885 \\
17 & 0.8021 & 0.4890 & 0.9952 \\
18 & 0.5740 & 0.3302 & 0.9840 \\
19 & 0.3099 & 0.4839 & 0.9962 \\
20 & 0.0516 & 0.6643 & 0.9997 \\
21 & 0.9947 & 0.4708 & 0.9821 \\
22 & 0.8044 & 0.3404 & 0.9728 \\
23 & 0.6972 & 0.5186 & 0.9859 \\
24 & 0.3693 & 0.7298 & 0.9959 \\
25 & 0.0971 & 1.0000 & 1.0000 \\
\hline & & & \\
\hline
\end{tabular}

Finally, calculate the grey relation grade (GRG) according to the values of GRC and weights.

$$
\begin{gathered}
\gamma_{i}=\sum_{k=1}^{z} w_{k} \xi_{i}(k) \\
\sum_{k=1}^{z} w_{k}=1
\end{gathered}
$$

where $\gamma_{i}$ is GRG and $w_{k}$ is weight. The weight of the output can be determined by the expert system according to actual production demand. In this optimization example, the weights of the three optimization objectives are the same, namely $w_{1}: w_{2}: w_{3}=1: 1: 1$.

The gray correlation coefficients $\left(\mathrm{GRC}_{\mathrm{MRR}}, \mathrm{GRC}_{\mathrm{Ra}}\right.$, and $\left.\mathrm{GRC}_{\mathrm{SEC}}\right)$ and $\mathrm{GRG}$ of each set of experiments can be obtained by Equations (8)-(13). The results of grey relational analysis and sorting of GRG are shown in Table 6.

\subsection{Process Modelling and ANOVA}

The original relationship between cutting parameters and three optimization objectives has been transformed into a new relationship between cutting parameters and GRG through grey relational analysis. In order to find the optimal cutting parameters, the regression model of GRG based on cutting parameters needs to be established first. The RSM was applied to fit the regression model, and Equation (14) represents the general form of the second-order RSM model.

$$
\mathrm{y}=\beta_{0}+\sum_{i=1}^{k} \beta_{i} x_{i}+\sum_{i<j} \sum \beta_{i j} x_{i} x_{j}+\sum_{i=1}^{k} \beta_{i i} x_{i}^{2}+\varepsilon
$$


where $x$ are independent variables, namely cutting parameters, $k$ is the number of independent variables, $\beta$ is a coefficient of each term, and $\varepsilon$ is a residual error.

Table 6. Results of grey relational analysis.

\begin{tabular}{cccccc}
\hline Contrast Sequence & $\mathrm{GRC}_{\boldsymbol{M R R}}$ & $\mathrm{GRC}_{\boldsymbol{R} \boldsymbol{a}}$ & $\mathrm{GRC}_{\text {SEC }}$ & $\mathrm{GRG}$ & Sort \\
\hline 1 & 0.3333 & 0.8648 & 0.3333 & 0.5105 & 20 \\
2 & 0.3369 & 0.6673 & 0.3972 & 0.4671 & 22 \\
3 & 0.3413 & 0.5100 & 0.4450 & 0.4321 & 23 \\
4 & 0.3492 & 0.4125 & 0.4885 & 0.4167 & 24 \\
5 & 0.3531 & 0.3333 & 0.5183 & 0.4016 & 25 \\
6 & 0.3528 & 0.8805 & 0.6037 & 0.6123 & 12 \\
7 & 0.3685 & 0.6576 & 0.6609 & 0.5623 & 16 \\
8 & 0.3892 & 0.5112 & 0.7032 & 0.5345 & 17 \\
9 & 0.4167 & 0.4115 & 0.7329 & 0.5204 & 19 \\
10 & 0.3802 & 0.3464 & 0.7446 & 0.4904 & 21 \\
11 & 0.3811 & 0.9404 & 0.6790 & 0.6668 & 8 \\
12 & 0.4165 & 0.6556 & 0.7251 & 0.5991 & 13 \\
13 & 0.4675 & 0.4968 & 0.7504 & 0.5716 & 15 \\
14 & 0.4090 & 0.4081 & 0.7641 & 0.5271 & 18 \\
15 & 0.4567 & 0.3470 & 0.9917 & 0.5984 & 14 \\
16 & 0.4231 & 1.0000 & 0.9775 & 0.8002 & 2 \\
17 & 0.4945 & 0.7164 & 0.9905 & 0.7338 & 4 \\
18 & 0.4274 & 0.5400 & 0.9689 & 0.6454 & 10 \\
19 & 0.4921 & 0.4201 & 0.9925 & 0.6349 & 11 \\
20 & 0.5983 & 0.3452 & 0.9994 & 0.6476 & 9 \\
21 & 0.4858 & 0.9895 & 0.9654 & 0.8136 & 1 \\
22 & 0.4312 & 0.7188 & 0.9484 & 0.6995 & 6 \\
23 & 0.5095 & 0.6228 & 0.9725 & 0.7016 & 5 \\
24 & 0.6492 & 0.4422 & 0.9918 & 0.6944 & 7 \\
25 & 1.0000 & 0.3564 & 1.0000 & 0.7855 & 3 \\
\hline & & & & \\
\hline
\end{tabular}

The cutting depth, feed speed, and cutting speed were coded using Equations (15)-(17), respectively. The values of cutting parameters were normalized to the range of -1 to 1 , which could cause the controlled factors to affect the responses more evenly [23]. The software Minitab17 was applied to fit the experimental data, with coded variables $\mathrm{A}, \mathrm{B}$, and $\mathrm{C}$ as continuous factors and GRG as output. The regression model for GRG was developed as Equation (18).

$$
\begin{aligned}
A & =\frac{a_{p}-1.2}{1} \\
B & =\frac{f-0.25}{0.1} \\
C & =\frac{v-70}{20} \\
\text { GRG }=0.5912+0.14701 A-0.04508 B+0.02142 C & -0.0150 A^{2}+0.0507 B^{2}-0.0126 C^{2}+0.0124 A B+0.0162 A C
\end{aligned}
$$

The predicted values for GRG of 25 sets of experiments can be computed according to Equation (18). The comparison of measured-predicted values from the regression model is depicted in Figure 3, and the average deviation of predicted values is $0.0937 \%$.

The ANOVA results of the regression model are shown in Table 7. Based on the statistical analysis results, the coefficient of determination R-sq for this regression model is $97.21 \%$, and the adjusted coefficient of determination R-sq (adj) is $95.82 \%$, which indicates that the regression model can be used to predict GRG according to cutting parameters. 


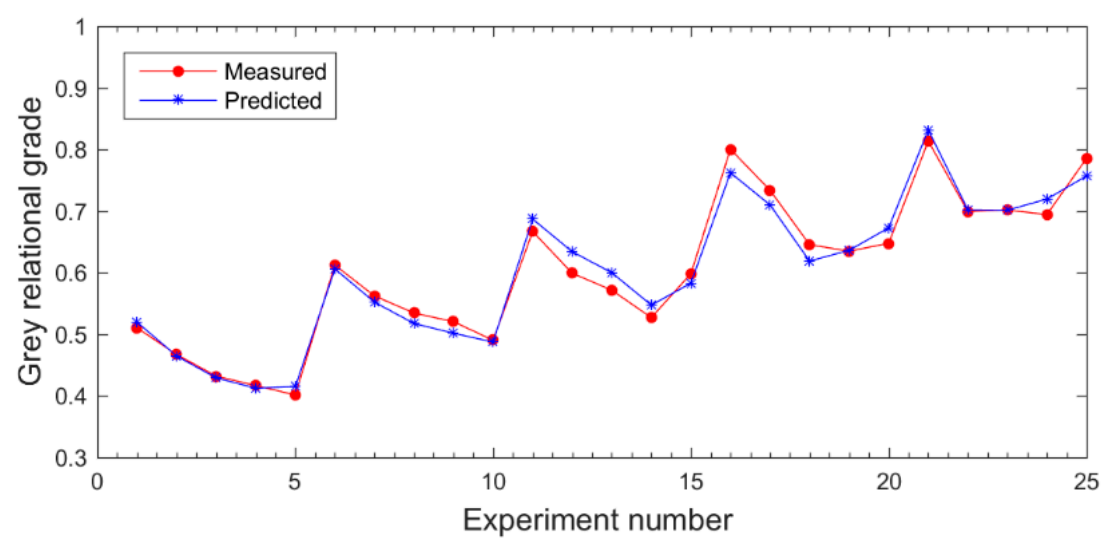

Figure 3. Comparisons of measured-predicted values for grey relation grade (GRG).

Table 7. ANOVA results for the GRG model.

\begin{tabular}{cccccc}
\hline Source & DF & SS & MS & F & P \\
\hline Regression model & 8 & 0.324835 & 0.040604 & 69.81 & $<0.001$ \\
Error & 16 & 0.009307 & 0.000582 & - & - \\
Total & 24 & 0.334142 & - & - & - \\
S $=0.0241181$ & \multicolumn{2}{c}{ R-sq $=97.21 \%$} & & R-sq (adj) $=95.82 \%$ & \\
\hline
\end{tabular}

\subsection{Optimization Results and Comparative Analysis}

The optimization of the aforementioned regression model was solved with response optimizer in minitab17 software. The constraint was the value range of the independent variables $A, B$, and $C$. The solution goal was the maximum value of GRG. The optimization results are shown in Figure 4.

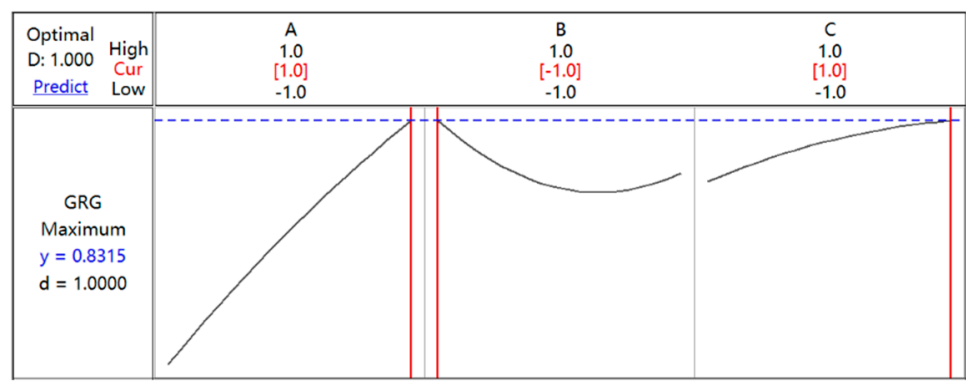

Figure 4. Multi-objective optimization results of cutting parameters.

As can be seen from Figure 4, the regression model obtains the maximum GRG of 0.8315 when $A=1, B=-1$, and $C=1$. The optimal solution corresponds to the following cutting parameters: $a_{p}=2.2$ $\mathrm{mm}, f=0.15 \mathrm{~mm} / \mathrm{rev}$, and $v=90 \mathrm{~m} / \mathrm{min}$, which are also consistent with experiment number 21 .

The comparison of experimental results using the initial and the optimal turning parameters is listed in Table 8 . The initial parameters are suggested by tool maker, and the optimal parameters are determined by the multi-objective optimization method developed. For the comparison between initial setting and the optimal solution, MRR increased from $433.9042 \mathrm{~mm}^{3} / \mathrm{s}$ to $472.1559 \mathrm{~mm}^{3} / \mathrm{s}$, Ra decreased from $2.4110 \mu \mathrm{m}$ to $0.7980 \mu \mathrm{m}$, and SEC decreased from $13.2391 \mathrm{~J} / \mathrm{mm}^{3}$ to $2.4545 \mathrm{~J} / \mathrm{mm}^{3}$, respectively. The optimization results show that a trade-off point can be drawn between the good cutting quality, high production rate, and low energy consumption with the proposed optimization method. 
Table 8. Results with different cutting parameters.

\begin{tabular}{|c|c|c|c|c|c|c|}
\hline \multirow{2}{*}{ Items } & $a_{p}$ & $f$ & $v$ & $R a$ & MRR & SEC \\
\hline & $(\mathrm{mm})$ & $(\mathrm{mm} / \mathrm{rev})$ & $(\mathrm{m} / \mathrm{min})$ & $(\mu \mathrm{m})$ & $\left(\mathrm{mm}^{3} / \mathrm{s}\right)$ & $\left(\mathrm{J} / \mathrm{mm}^{3}\right)$ \\
\hline Initial parameters & 1.2 & 0.25 & 90 & 2.4110 & 433.9042 & 13.2391 \\
\hline Optimal parameters & 2.2 & 0.15 & 90 & 0.7980 & 472.1559 & 2.4545 \\
\hline Promotion & - & - & - & $66.90 \%$ & $8.82 \%$ & $81.46 \%$ \\
\hline
\end{tabular}

\section{Conclusions}

In this research, the multi-objective optimization framework of turning parameters was investigated. The multi-objective optimization method based on grey relational analysis and RSM was proposed and verified in wet turning AISI 304 austenitic stainless steel. The main conclusions are as follows.

(1) In order to effectively balance the cutting quality, production rate, and energy consumption in turning process, Ra, MRR, and SEC are featured as optimization objectives of turning parameters for sustainable manufacturing.

(2) The complex multi-objective optimization problem can be transformed to a single objective optimization problem with grey relational analysis, which simplifies the optimization procedure.

(3) The coefficient of determination R-sq of the GRG model is $97.21 \%$. This means that the regression model based on RSM can be used to predict the value of GRG with high accuracy.

(4) In this optimization example, the optimal combination of cutting parameters in turning AISI 304 austenitic stainless steel is: $a_{p}=2.2 \mathrm{~mm}, f=0.15 \mathrm{~mm} / \mathrm{rev}$, and $v=90 \mathrm{~m} / \mathrm{s}$. Compared with the initial turning parameters, Ra decreases $66.90 \%$, MRR increases $8.82 \%$, and SEC decreases $81.46 \%$.

Author Contributions: Conceptualization, Y.S. and G.Z.; data curation, Y.S., G.Z. and C.L.; formal analysis, Y.S., C.L., G.Z., Y.Z. and J.M.; funding acquisition, G.Z.; investigation, G.Z., J.M. and Y.Z.; methodology, G.Z.; project administration, G.Z.; software, Y.S. and Y.Z.; validation, Y.Z., J.M. and C.L.; writing-original draft, Y.S. and C.L.; writing-review and editing, Y.S., C.L., G.Z., Y.Z. and J.M. All authors have read and agreed to the published version of the manuscript.

Funding: This research was funded by Shandong Provincial Natural Science Foundation of China (grant number ZR2016EEM29) and Shandong Provincial Key Research and Development Program of China (grant number 2017GGX30114).

Acknowledgments: The authors are grateful to Yunli Xu, Yong Zhao, and Shuo Yu for technical support during experiments.

Conflicts of Interest: The authors declare no conflict of interest.

\section{References}

1. Öktem, H.; Erzurumlu, T.; Kurtaran, H. Application of response surface methodology in the optimization of cutting conditions for surface roughness. J. Mater. Process. Technol. 2005, 170, 11-16. [CrossRef]

2. Zhao, G.; Liu, Z.; He, Y.; Cao, H.; Guo, Y. Energy consumption in machining: Classification, prediction, and reduction strategy. Energy 2017, 133, 142-157. [CrossRef]

3. Camposeco-Negrete, C.; de Dios Calderón-Nájera, J. Sustainable machining as a mean of reducing the environmental impacts related to the energy consumption of the machine tool: A case study of AISI 1045 steel machining. Int. J. Adv. Manuf. Technol. 2019, 102, 27-41. [CrossRef]

4. Kumar, S. Measurement and uncertainty analysis of surface roughness and material removal rate in micro turning operation and process parameters optimization. Measurement 2019, 140, 538-547. [CrossRef]

5. Zhou, T.; He, L.; Wu, J.; Du, F.; Zou, Z. Prediction of surface roughness of 304 stainless steel and multi-objective optimization of cutting parameters based on GA-GBRT. Appl. Sci. 2019, 9, 3684-3705. [CrossRef]

6. Li, H.; Wang, J. Determination of optimum parameters in plane grinding by using grey relational analysis. Chin. Mech. Eng. 2011, 22, 631-635.

7. Kuram, E.; Ozcelik, B. Multi-objective optimization using Taguchi based grey relational analysis for micro-milling of Al 7075 material with ball nose end mill. Measurement 2013, 46, 1849-1864. [CrossRef] 
8. Tuo, J.; Liu, F.; Zhang, H.; Liu, P.; Cai, W. Connotation and Assessment Method for Inherent Energy Efficiency of Machine tool. J. Mech. Eng. 2018, 54, 167-175. [CrossRef]

9. Vijayaraghavan, A.; Dornfeld, D. Automated energy monitoring of machine tool. CIRP Ann. 2010, 59, 21-24. [CrossRef]

10. Kara, S.; Li, W. Unit process energy consumption models for material removal processes. CIRP Ann. 2011, 60,37-40. [CrossRef]

11. Li, L.; Yan, J.; Xing, Z. Energy requirements evaluation of milling machines based on thermal equilibrium and empirical modelling. J. Clean. Prod. 2013, 52, 113-121. [CrossRef]

12. Zhang, H.; Kong, L.; Li, T.; Chen, J. SCE modeling and influence trend analysis of cutting parameters. Chin. Mech. Eng. 2015, 26, 1098-1103.

13. Camposeceo-Negrete, C. Optimization of cutting parameters using response surface method for minimizing energy consumption and maximizing cutting quality in turning of AISI 6061 T6 aluminum. J. Clean. Prod. 2015, 91, 109-117. [CrossRef]

14. Zhao, G.; Guo, Y.; Zhu, P.; Zhao, Y. Energy consumption characteristics and influence on surface quality in milling. Proc. CIRP 2018, 71, 111-115. [CrossRef]

15. Zhou, L.; Li, J.; Li, F.; Mendis, G.; Sutherland, J.W. Optimization parameters for energy efficiency in end milling. Proc. CIRP 2018, 69, 312-317. [CrossRef]

16. Li, C.; Xiao, Q.; Tang, Y.; Li, L. A method integrating Taguchi, RSM and MOPSO to CNC machining parameters optimization for energy saving. J. Clean. Prod. 2016, 135, 263-275. [CrossRef]

17. Yan, J.; Li, L. Multi-objective optimization of milling parameters-The trade-offs between energy, production rate and cutting quality. J. Clean. Prod. 2013, 52, 462-471. [CrossRef]

18. Li, X.; Liu, Z.; Liang, X. Tool wear, surface topography, and multi-objective optimization of cutting parameters during machining AISI 304 austenitic stainless steel flange. Metals 2019, 9, 972-987. [CrossRef]

19. Liu, N.; Wang, S.; Zhang, Y.; Lu, W. A novel approach to predicting surface roughness based on specific cutting energy consumption when slot milling Al-7075. Int. J. Mech. Sci. 2016, 118, 13-20. [CrossRef]

20. Fang, X.; Safi-Jahanshaki, H. A new algorithm for developing a reference model for predicting surface roughness in finish machining of steels. Int. J. Prod. Res. 1997, 35, 179-197. [CrossRef]

21. Hu, S.; Liu, F.; He, Y.; Hu, T. An on-line approach for energy efficiency monitoring of machine tool. J. Clean. Prod. 2012, 27, 133-140. [CrossRef]

22. Nayak, S.K.; Patro, J.K.; Dewangan, S.; Gangopadhyay, S. Multi-objective optimization of machining parameters during dry turning of AISI 304 austenitic stainless steel using grey relational analysis. Proc. Mater. Sci. 2014, 6, 701-708. [CrossRef]

23. Baş, D.; Boyaci, I.H. Modeling and optimization I: usability of response methodology. J. Food Eng. 2007, 78, 836-845. [CrossRef]

(C) 2020 by the authors. Licensee MDPI, Basel, Switzerland. This article is an open access article distributed under the terms and conditions of the Creative Commons Attribution (CC BY) license (http://creativecommons.org/licenses/by/4.0/). 